\title{
IVABRADINE HYDROCHLORIDE DIRECTLY COMPRESSED TABLETS USING NANO-CELLULOSE EXTRACTED FROM ARACHIS HYPOGAEA SHELLS
}

\author{
JEEVANA JYOTHI B*, APARNA J \\ Department of Pharmaceutics, Institute of Pharmaceutical Technology, Sri Padmavati Mahila Visvavidyalayam (Women's University), \\ Tirupati, Andhra Pradesh, India. Email: jeevanajyothib@yahoo.com
}

Received: 30 October 2019, Revised and Accepted: 18 November 2019

\section{ABSTRACT}

Objective: The main objective of this work was the extraction of nanocellulose from Arachis hypogaea shells, characterization of nanocellulose, development, and in vitro evaluation of directly compressed tablets of ivabradine hydrochloride (IVH) using nanocellulose.

Methods: IVH and colloidal silicon dioxide are gift samples from Mylan Laboratory, Hyderabad, and Karnataka Antibiotics and Pharmaceuticals Ltd., Bengaluru, respectively. Nanocellulose was extracted from A. hypogaea shells by alkaline treatment followed by acid hydrolysis and it was characterized by particle size analysis by zeta sizer, melting point determination, differential scanning calorimetry (DSC), and Fourier transform infrared (FTIR) analysis. Compatibility between IVH and nanocellulose was confirmed by FTIR and DSC analysis. Then, fast-release tablets of containing 5 mg of IVH were prepared by direct compression using various compositions containing nanocellulose, starch, and colloidal silicon dioxide and evaluated.

Results: Nanocellulose in the size of $273.4 \mathrm{~nm}$ was extracted from A. hypogaea shells to possess its ideal characteristics. IVH and nanocellulose were compatible according to FTIR and DSC analysis. Fast-release tablets of IVH were prepared as directly compressed tablets by direct compression. Tablets made with $5 \mathrm{mg}$ of IVH and nanocellulose, starch, and colloidal silicon dioxide evidenced fast release of $96.37 \%$ in 5 min.

Conclusion: Nanocellulose from A. hypogaea shells can be produced successfully by alkali treatment followed by acid hydrolysis, ball milling, and lyophilization. This nanocellulose can be exploited successfully for the design of fast-release tablets of IVH.

Keywords: Nanocellulose, Arachis hypogaea shells, Soxhlation method, Fourier transform infrared, Compatibility, Ivabradine hydrochloride, Fast release.

(C) 2020 The Authors. Published by Innovare Academic Sciences Pvt Ltd. This is an open access article under the CC BY license (http://creativecommons. org/licenses/by/4. 0/) DOI: http://dx.doi.org/10.22159/ajpcr.2020.v13i1.36219

\section{INTRODUCTION}

Pharmaceutical excipients play a key role in formulation development of therapeutics. Synthetic polymers and celluloses are exploited for the production of directly compressed vehicle to produce tablets without granulation due to their reported compatibility. Especially, naturally occurring celluloses are studied as pharmaceutical excipients due to their compressibility, low toxicity, biodegradability, and renewable nature [1]. It was reported that all-cellulose composites possess an intriguing combination of high strength and biodegradability [2]. Cellulose is listed as a direct compression vehicle to produce tablets by direct compression without granulation procedures. This saves lots of economy on the part of the manufacturing productions. Hence, in an attempt in an advanced study in this line, we have selected to evaluate nanocellulose to produce tablets by direct compression.

The advanced product called nanocellulose is further processed nanosized cellulose fibrils with a very high aspect ratio. Typically, lateral dimensions are 5-20 $\mathrm{nm}$ and longitudinal dimensions are in a wide range, typically several micrometers. Nanocellulose can be extracted from plant cell wall and can be extracted from a variety of sources, such as wood, bast fibers, grasses, seed fibers, marine animals, algae, fungi, invertebrates, and bacteria [3]. India, being an agricultural country, generates mind-boggling amount of agricultural waste, which is over 320 million tons per year. Main sources of agro-waste are paddy straw, sugarcane biogases, peanut shells, coffee husk, and maize husk.

Therefore, in the present work, Arachis hypogaea (peanuts) have been selected for extraction of nanocellulose from it and ivabradine hydrochloride (IVH) was selected as a model drug to exploit nanocellulose for the design of directly compressed tablets of IVH.
IVH is a new drug approved by the United States Food and Drug Administration in April 2015 for the treatment of chronic stable angina pectoris in coronary artery disease. The nature of nanocellulose is expected to produce compact tablet with fast release as there may be a need for quick therapeutic effect for the treatment of angina pectoris. IVH is generally used in adult patients who do not tolerate or cannot take heart medicines called beta-blockers.

\section{MATERIALS AND METHODS}

Materials

IVH and colloidal silicon dioxide are gift samples from Mylan Laboratory, Hyderabad, and Karnataka Antibiotics and Pharmaceuticals Ltd., Bengaluru, respectively. Urea nitric acid was purchased from SD Fine Chemical Laboratories. All other chemicals used in the study are of analytical grade.

\section{Methods}

Various stages of the present research include extraction of nanocellulose from $A$. hypogaea shells, characterization, development of fast-release tablets of IVH, and in vitro evaluation of prepared tablets.

\section{Isolation of nanocellulose}

A. hypogaea shells were collected from local peanut mill (Tirupati, Chittoor district, Andhra Pradesh). They were washed with water to remove the soil contents and then sundried for 5 days to remove moisture content. The dried shells were ground into fine powder using a mill and were sieved using sieve no. 120 [4].

Thirty grams of the powder were treated with $800 \mathrm{ml}$ of $0.5 \mathrm{M} \mathrm{NaOH}$ for $3 \mathrm{~h}$ at $90^{\circ} \mathrm{C}$ with continuous stirring. The obtained dark slurry was 
filtered and then washed several times with distilled water and then dried. The dried powder was again ground into a fine powder using a mill. Milled powder was refluxed with a mixture containing $30 \%(\mathrm{v} / \mathrm{v})$ of nitric acid in ethanol. After this treatment, the color of the powder changed from light red to yellow in color. This residue was until the constant weight is obtained. The dried powder was again subjected to grinding in ball mill for $20 \mathrm{~min}$ and further kept for drying in a lyophilizer (Lyodel, Japan) for $24 \mathrm{~h}$. Fig. 1 shows images of the product obtained at various stages of extraction. This yield was stored in polyethylene bags for characterization $[5,6]$.

\section{Characterization of nanocellulose}

Percentage yield

The percentage yield of cellulose was calculated by the percentage ratio of actual yield to theoretical yield [7].

$$
\text { \%yield of cellulose }=\frac{\mathrm{W} 2}{\mathrm{~W} 1} \times 100
$$

Where,

$\mathrm{W}_{2}$ is the weight of the resultant cellulose and

$\mathrm{W}_{1}$ is the initial weight of peanut shell powder.

\section{Determination of particle size by zeta sizer}

Particle size of cellulose was determined using zeta sizer (Horiba). One milligram of sample was weighed and suspended in $5 \mathrm{ml}$ of distilled water. This liquid sample was taken in $1 \mathrm{~cm}$ cuvettes and the particle size and zeta potential were determined [8].

\section{Determination of moisture content}

Grounded powder, $3 \mathrm{~g}$ was weighed accurately in a dry Petri dish and dried at $105^{\circ} \mathrm{C}$ for $6 \mathrm{~h}$. The sample was allowed to cool, reweighed the sample and weight of sample was recorded $[9,10]$. The procedure was repeated until the weight of sample was constant. The moisture content was measured using the following equation:

$$
\text { Moisture content }(\%)=\frac{W 1-W 2}{W 1} \times 100
$$

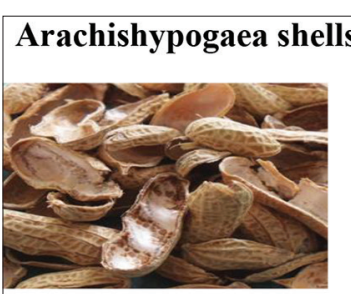

Alkali treated

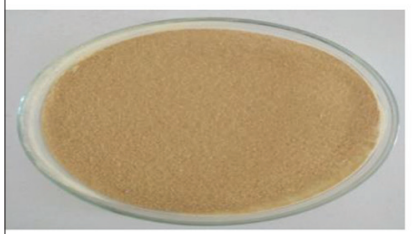

Nano-cellulose

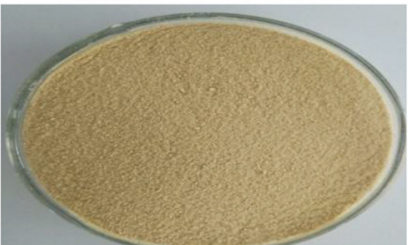

Fig. 1: Various stages and images during the extraction of nanocellulose from Arachis hypogaea shells
Where,

$\mathrm{W}_{1}$ is the initial weight of peanut shells powder and

$\mathrm{W}_{2}$ is the final weight of peanut shell powder.

\section{Determination of ash content}

Crucible was weighed accurately (W1 g). About $2 \mathrm{~g}$ of peanut shell powder was weighed accurately along with crucible $\left(\mathrm{W}_{2 \mathrm{~g}}\right)$. The sample was used with the help of muffle furnace at $600^{\circ} \mathrm{C}$ for $6 \mathrm{~h}$, cooled the crucible for $1 / 2 \mathrm{~h}$, and weighed the ash containing crucible $\left(\mathrm{W}_{3}\right)$. The ash content is calculated using the following formula $[11,12]$

$$
\text { Ash content }(\%)=\frac{\mathrm{W} 3-\mathrm{W} 1}{\mathrm{~W} 2-\mathrm{W} 1} \times 100
$$

Where, $\mathrm{W}_{1}$ was the weight of crucible

$\mathrm{W}_{2}$ was the weight of peanut shell powder and crucible and $\mathrm{W}_{3}$ was the weight of ash and crucible.

\section{Determination of melting point}

The melting point of prepared nanocellulose sample was determined by open capillary tube method.

\section{Solubility of nanocellulose}

Cellulose is insoluble in water and it was reported that it is soluble in $10 \% \mathrm{NaOH}$ and $12 \%$ urea in water. Hence, in the present study, the prepared nanocellulose $(4 \%)$ was dissolved in water containing $7 \%$ $\mathrm{NaOH}$ and $12 \%$ urea. After 10 min of vigorous stirring, the suspension of cellulose and solvent was cooled to $-10^{\circ} \mathrm{C}$ and stirring was continued for $1 \mathrm{~h}$ for complete solubility [2].

\section{Fourier-transform infrared (FTIR) spectroscopy of cellulose}

The chemical constituents of nanocellulose were investigated by FTIR spectroscopy (Bruker, Japan). Sample was prepared by a pressed pellet technique. The FTIR spectrum of the nanocellulose was recorded in transmittance mode in the range of $400-4000 \mathrm{~cm}^{-1}$.

\section{Differential scanning calorimetry (DSC) of nanocellulose}

DSC analysis of nanocellulose was carried out using DSC analyzer (Mettler Toledo, Switzerland). Heat flow rate was $10^{\circ} \mathrm{C} / \mathrm{min}$ and sample was heated from $200^{\circ} \mathrm{C}$ to $400^{\circ} \mathrm{C}$ to detect possible interaction of polymer [13].

\section{Interaction studies between IVH and nanocellulose}

To assess compatibility between IVH and cellulose extracted from peanut shells, FTIR spectra and DSC thermogram were obtained for pure IVH and a 1:1 1 mixture of IVH and nanocellulose and investigated for interaction.

\section{Development of directly compressed tablets of IVH using} nanocellulose

As there is no interaction between IVH and nanocellulose of $A$. hypogaea shells, tablets containing $5 \mathrm{mg}$ of IVH were prepared by direct compression using this nanocellulose as the main vehicle to produce tablets without the use of granulating agents. Eight formulations F1-F8 were tried and their composition is given in Table 1. The ingredients are weighed accurately and mixed uniformly using mortar and pestle and later to obtain a uniform mix of all the ingredients. The mixtures are evaluated for pre-compression characteristics. As they are satisfactory, they were compressed into tablets using $9 \mathrm{~mm}$ single punch tablet machine.

\section{Evaluation of pre-compression characteristics}

Pre-compression characteristics of powder of formulations F1-F8 were assessed by the determination of compressibility index, angle of repose, and Hausner's ratio.

\section{Compressibility index and Hausner's ratio}

Powdered mixture of $10 \mathrm{~g}$ was taken in a $100 \mathrm{ml}$ measuring cylinder. The volume of the powder was noted (bulk volume). The cylinder was 
Table 1: Formulation of ivabradine hydrochloride directly compressed tablets

\begin{tabular}{|c|c|c|c|c|}
\hline Formulation & IVH (mg) & Colloidal silicon dioxide (mg) & Nanocellulose (mg) & Starch (mg) \\
\hline F1 & 5 & 10 & 165 & 10 \\
\hline $\mathrm{F} 2$ & 5 & 10 & 170 & 5 \\
\hline F3 & 5 & 20 & 155 & 15 \\
\hline $\mathrm{F} 4$ & 5 & 10 & 180 & 5 \\
\hline F5 & 5 & 25 & 135 & 10 \\
\hline F6 & 5 & 10 & 180 & 5 \\
\hline F7 & 5 & 20 & 170 & 5 \\
\hline
\end{tabular}

IVH: Ivabradine hydrochloride

subjected to a fixed number of taps (100). Then, the final volume of the powder was recorded (tapped volume). Then, the bulk density, true density, compressibility index, and Hausner's ratio were calculated using the following equation:

$$
\begin{gathered}
\text { Bulk density }=\frac{\text { Weight of thepowder }}{\text { Bulk volume }} \\
\text { Tapped density }=\frac{\text { Weight of thepowder }}{\text { Tapped volume }} \\
\text { Compressibility index }=\frac{\text { Tapped density }- \text { Bulkdensity }}{\text { Tapped volume }} \times 100 \\
\text { Hausner' sratio }=\frac{\text { Tappeddensity }}{\text { Bulk volume }}
\end{gathered}
$$

\section{Angle of repose}

Using a fixed height funnel method, the angle of repose was calculated. The funnel height was kept constant $2 \mathrm{~cm}(\mathrm{~h})$ and the diameter (D) of the circle was measured and the angle of repose was find out using the following equation:

$$
\theta=\tan ^{-1} \frac{\mathrm{h}}{\mathrm{r}}
$$

Where,

$\mathrm{h}=$ height of the cone

$\mathrm{r}=$ radius of the base.

\section{Evaluation of prepared directly compressed tablets}

The following evaluation tests were performed for the tablets: Weight variation test, hardness, drug content, friability, disintegration test, and dissolution rate testing.

\section{Weight variation test}

Weight variation was calculated as per the method described in I. P [14]. Twenty tablets were selected at random and their average weight was determined. The tablets were weighed individually and compared with average weight to assess acceptance criteria as per official criteria as given below.

\begin{tabular}{ll}
\hline Average weight of tablet $(\mathbf{m g})$ & Percentage difference allowed \\
\hline 80 or less & \pm 10 \\
$80-250$ & \pm 7.5 \\
$>250$ & \pm 5 \\
\hline
\end{tabular}

\section{Hardness test}

The hardness of tablets was measured using the Monsanto hardness tester.

\section{Thickness}

The thickness of tablets was determined using a digital Vernier caliper.

\section{Drug content}

The tablet was taken in a mortar and pestle, it was made into powder and transferred into a $100 \mathrm{ml}$ volumetric flask and made up to the mark with 6.8 phosphate buffer. This solution was estimated for drug content by an ultraviolet spectrophotometer at $286 \mathrm{~nm}$.

\section{Friability test}

A pre-weighed 10 tablets were placed in the Friabilator (Veego Instruments Ltd., India) which is then operated for 100 revolutions. The tablets were dusted and reweighed again.

$$
\text { Friability }=(\mathrm{W} 1-\mathrm{W} 2) / \mathrm{W} 1 \times 100
$$

Where,

Weight of 10 tablets $=\mathrm{W} 1$

Weight of 10 tablets after friability $=\mathrm{W} 2$.

\section{Disintegration test}

Disintegration test was carried out using disintegration test apparatus (Thermionic, India). Randomly selected six tablets were placed into a testing basket assembly, which is introduced into a special holder and placed into a water bath. The water inside the water bath is heated to $37^{\circ} \mathrm{C} \pm 0.5^{\circ} \mathrm{C}$. The basket assembly was moved smoothly up and down for 28-32 stokes/min and for a distance of $55 \mathrm{~mm}$. The samples are disintegrated if no solid rest is left within the basket. The time taken for the tablets to disintegrate was noted.

\section{In vitro drug release studies}

In vitro drug release studies were conducted for prepared tablets F1-F8 which were using USP dissolution testing apparatus, Type II (Electrolab, India) [15]. The dissolution medium was $900 \mathrm{ml}$ of $\mathrm{pH} 6.8$ phosphate buffer maintained at a temperature of $37^{\circ} \mathrm{C} \pm 0.5^{\circ} \mathrm{C}$. The paddle was rotated at a speed of $50 \mathrm{rpm}$. At specific time intervals, $5 \mathrm{ml}$ aliquot samples were withdrawn and were replaced with fresh dissolution medium to maintain sink conditions. The samples were suitably diluted wherever necessary and estimated for IVH content by measuring the absorbance at $286 \mathrm{~nm}$ using UV spectrophotometer (Shimadzu). The test was also conducted for commercial tablets of IVH for comparison purpose.

\section{Drug release kinetics}

To study the release kinetics, data obtained from in vitro dissolution studies were fitted to various kinetic models such as zero-order, firstorder, Higuchi model, and Korsmeyer-Peppas model.

\section{RESULTS AND DISCUSSION}

Nanocellulose extracted was in light yellowish color with a characteristic odor. It was assessed for its characteristics such as percentage moisture content, percentage ash content, percentage yield, melting point, solubility, particle size determination, FTIR spectrophotometer, and DSC to access its use in design of directly compressed tablets of IVH.

\section{Percentage yield}

The sequential treatment of peanut shells powder with $\mathrm{NaOH}, 25 \%$ nitric acid in ethanol resulted in dissolution or degradation of proteins and lignin. Yielding of extracted nanocellulose was 35\%. In general, the nanocellulose content present in the peanut shells was $37 \%$. Hence, 


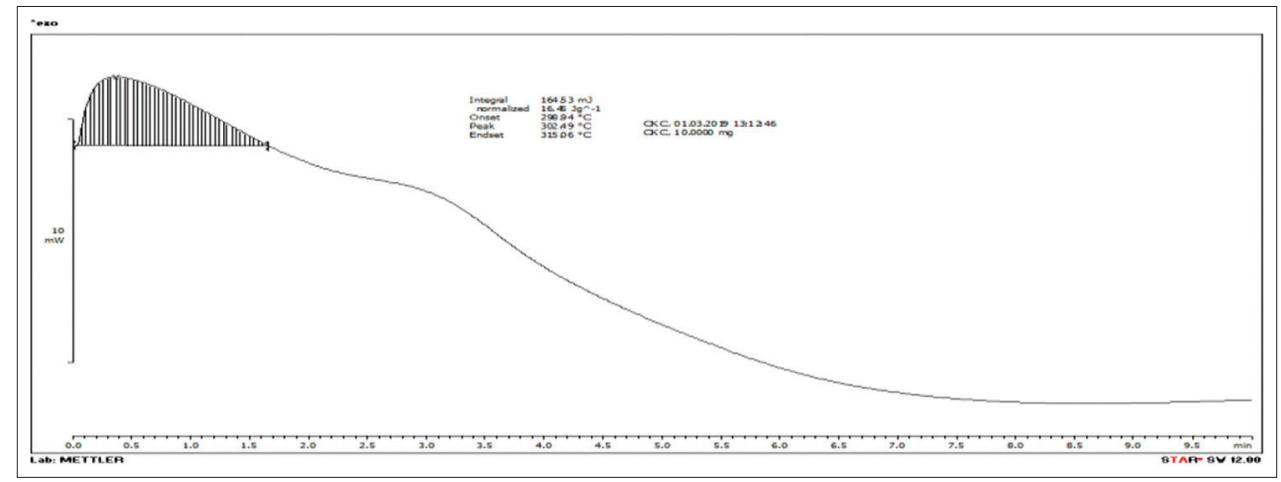

Fig. 2: Differential scanning calorimetry thermogram of nanocellulose

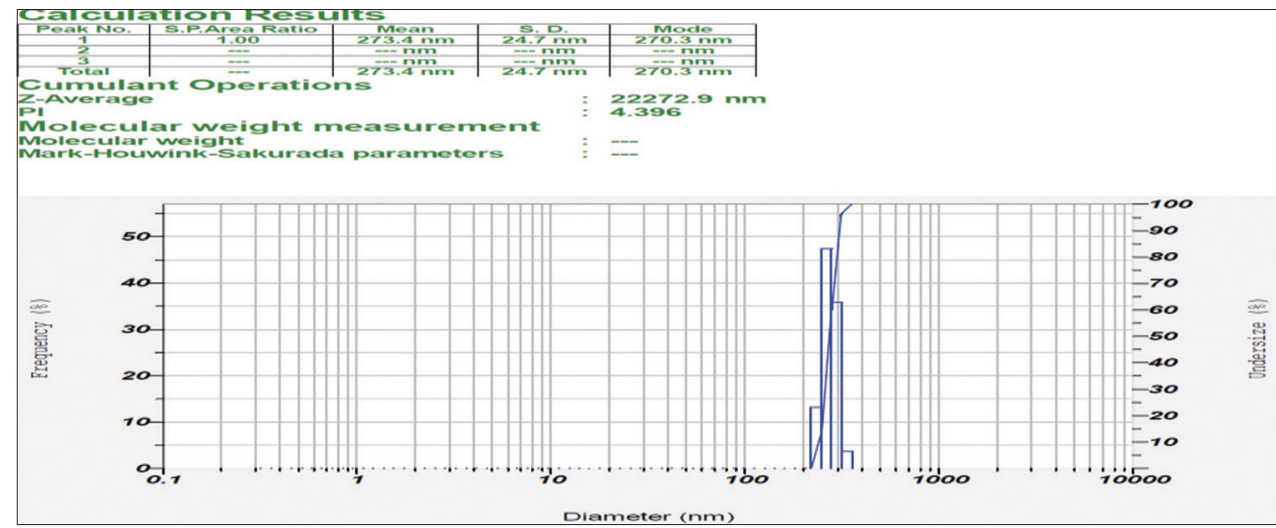

Fig. 3: Particle size of nanocellulose of Arachis hypogaea shells

the obtained percentage yield of nanocellulose was within the range as compared with reference value [2].

\section{Particle size determination of nanocellulose}

The scan of particle size analysis obtained from zeta sizer, as shown in Fig. 2. As indicated in Fig. 3, the mean particle size of the prepared nanocellulose is $273.4 \mathrm{~nm}$. This indicates that the present method used for isolation of nanocellulose is successful in producing cellulose in nanosize.

\section{Percentage moisture content}

The percentage moisture content of nanocellulose was found to be $4.38 \%$. This value below $10 \%$ indicates its good shelf-life, usability, and quality [2].

\section{Percentage ash content}

The percentage ash content of nanocellulose was found to be $0.1 \%$. The ash content of the peanut nanocellulose was reported to be below $5 \%$. This indicates the prepared nanocellulose having reasonable value of ash content.

\section{Melting point}

The melting point of the isolated nanocellulose was found to be $316.49^{\circ} \mathrm{C}$ and is coinciding with the reported melting point of cellulose, i.e., $316^{\circ} \mathrm{C}[2]$.

\section{Solubility of nanocellulose}

It was observed that the prepared nanocellulose was completely dissolved in $10 \% \mathrm{NaOH}$ and $12 \%$ urea.

\section{FTIR spectroscopy of nanocellulose}

FTIR spectrum of extracted nanocellulose is shown in Fig. 4. It revealed its $\mathrm{OH}$ stretching vibration at $3341 \mathrm{~cm}^{-1}$ and $\mathrm{C}-\mathrm{H}$ stretching vibrations at $2911 \mathrm{~cm}^{-1}$ and $1643 \mathrm{~cm}^{-1}$. The data coincide with reported IR absorption peaks, as shown in Table 2, confirm the structural conformity of the prepared nanocellulose.
Table 2: Infrared absorption peaks of nanocellulose

\begin{tabular}{lll}
\hline Functional group & Reported $\left(\mathbf{c m}^{-\mathbf{1}}\right)$ & Obtained $\left(\mathbf{c m}^{-\mathbf{1}}\right)$ \\
\hline O-H stretching & 3400 & 3341 \\
C-H stretching & 2900 and 1627 & 2911 and 1643 \\
\hline
\end{tabular}

Table 3: Data for Fourier transform infrared of IVH and mixture of IVH and nanocellulose

\begin{tabular}{lll}
\hline Functional group & Pure IVH $\mathbf{( \mathbf { c m } ^ { - 1 } )}$ & $\begin{array}{l}\text { IVH with } \\
\text { nanocellulose }\end{array}$ \\
\hline O-CH3 stretching & 1250 and 1059 & 1250 and 1061 \\
C=O stretching & 1656 & 1651 \\
C=C stretching & 1520 & 1519 \\
C-N stretching of tertiary & 1059 & 1061 \\
aliphatic amine & & \\
Symmetric C-H stretching & 2947 & 2947 \\
Stretching N-H & 3475 & 3482 \\
\hline
\end{tabular}

IVH: Ivabradine hydrochloride

\section{DSC of nanocellulose}

DSC thermogram of nanocellulose of peanut shells is shown in Fig. 5. As revealed in thermogram typical with onset temperature of decomposition wasstarted just above $300^{\circ} \mathrm{C}$ and then with endothermic peak was present at $302.49^{\circ} \mathrm{C}$. This coincides with the behavior of nanocellulose reported for peanut shells.

Interaction studies between IVH and nanocellulose

To assess the compatibility between IVH and cellulose extracted from peanut shells, FTIR spectra and DSC thermogram were obtained for pure IVH and a 1:1 1 mixture of IVH and nanocellulose.

FTIR spectra of IVH and mixture of IVH and NC are shown in Figs. 6 and 7. The data of peaks are summarized in Table 3. It is evident that all 


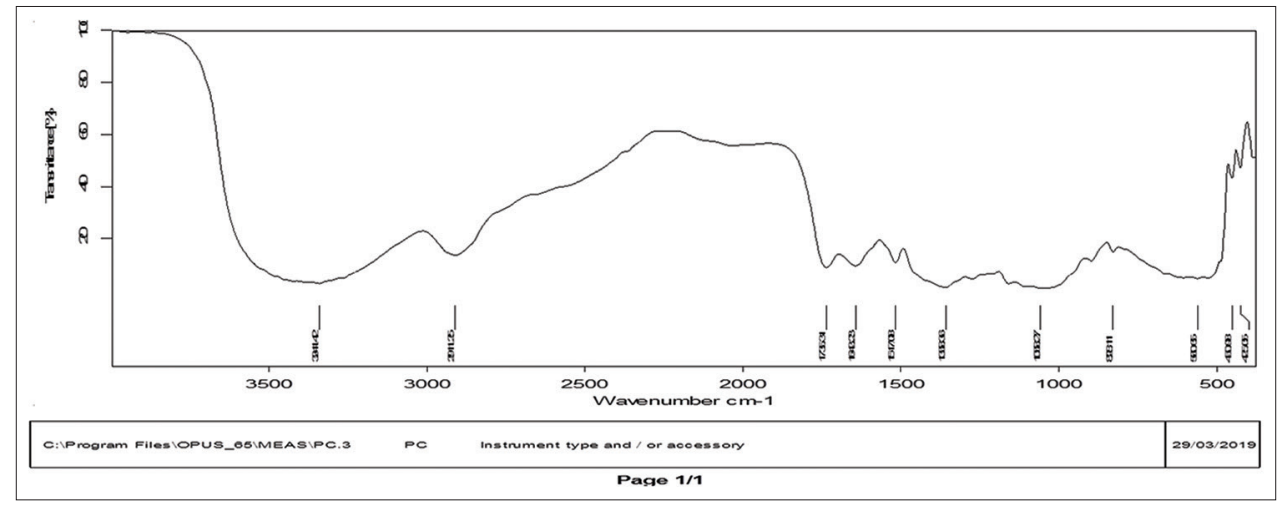

Fig. 4: Fourier-transform infrared spectroscopy of nanocellulose

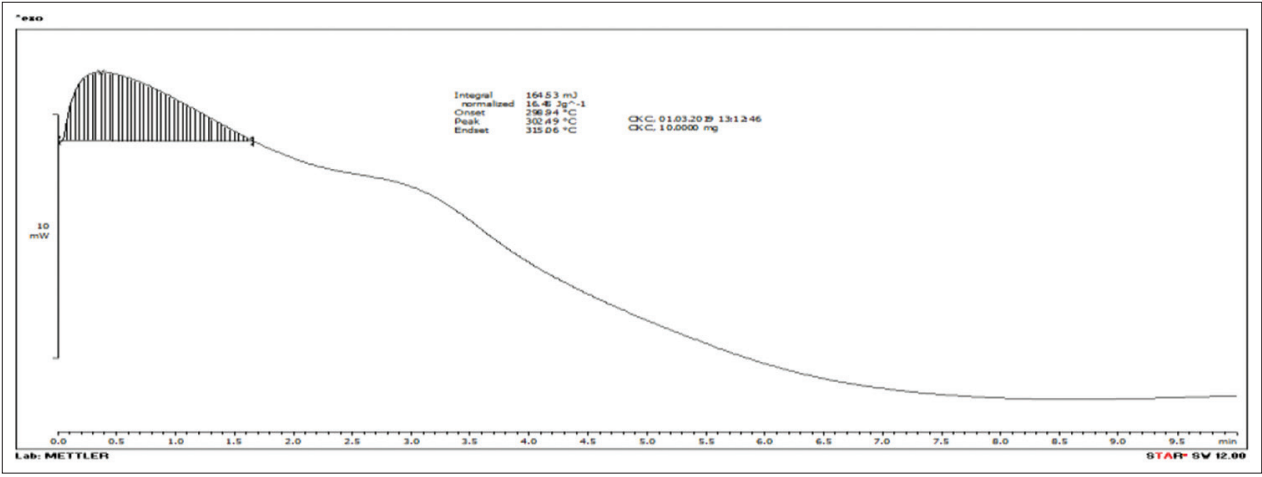

Fig. 5: Differential scanning calorimetry thermogram of nanocellulose

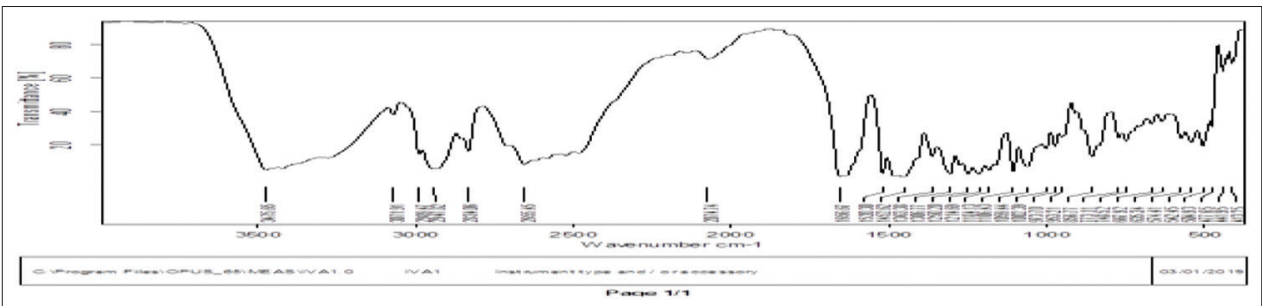

Fig. 6: Fourier transform infrared spectra of ivabradine hydrochloride

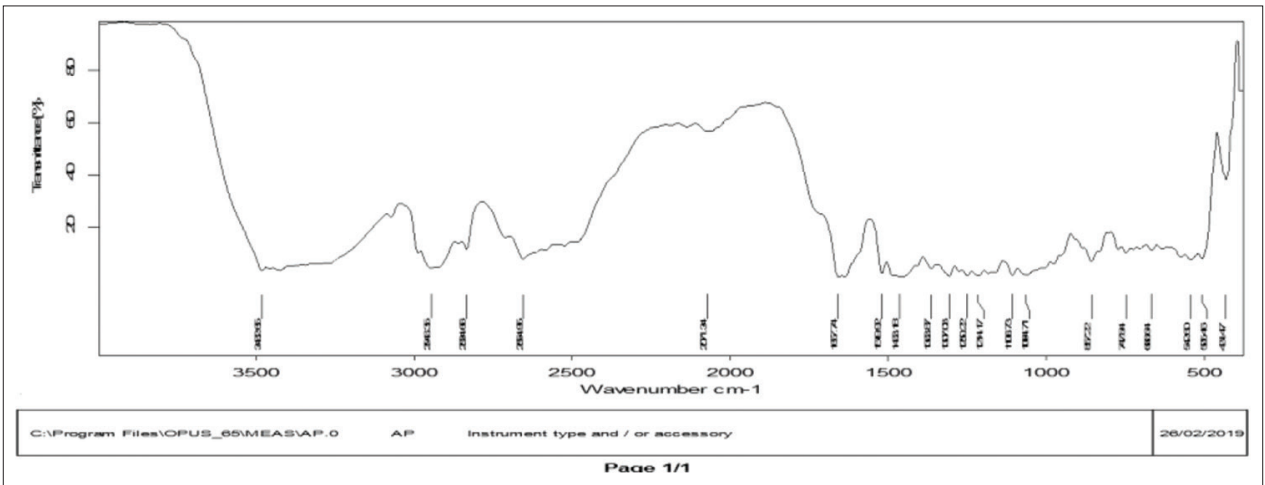

Fig. 7: Fourier transform infrared spectrum of ivabradine hydrochloride and nanocellulose mixture

the absorption peaks of main functional groups of IVH are present on mixing with prepared nanocellulose indicating no interaction.

DSC thermogram in Fig. 8 showed sharp endotherm of IVH at $198.17^{\circ} \mathrm{C}$. DSC thermogram of nanocellulose in Fig. 2 revealed its melting point peak at $302.49^{\circ}$ C. DSC thermogram of mixture of IVH and NC in Fig. 9 exhibits melting peaks at $190^{\circ} \mathrm{C}$ and $308^{\circ} \mathrm{C}$ corresponding to IVH and
NC. These results indicate that there is no drug excipient interaction between IVH and NC.

Evaluation of pre-compressed characteristics

The results of pre-compression characteristics of IVH tablets F1-F8 are given in Table 4. As shown in table, the angle of repose values ranging from $21.80^{\circ}$ to $30.96^{\circ}$, compressibility index from $9 \%$ to $20 \%$, and 


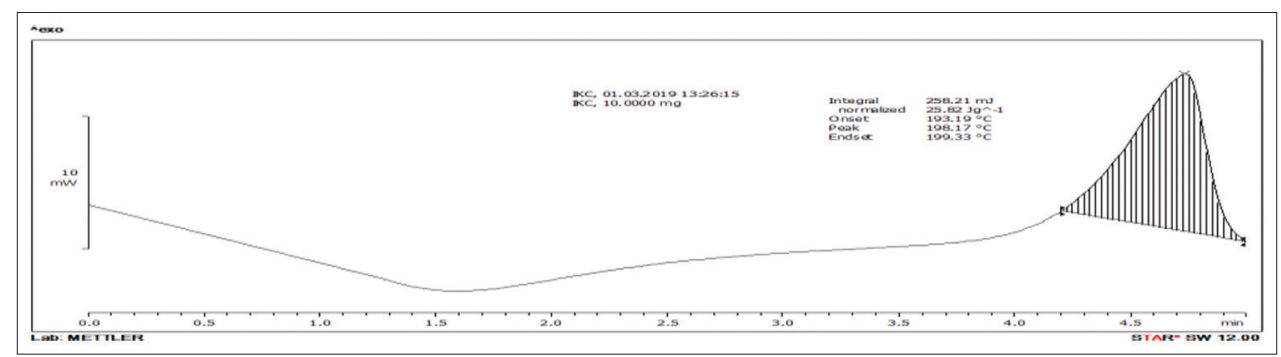

Fig. 8: Differential scanning calorimetry graph of ivabradine hydrochloride

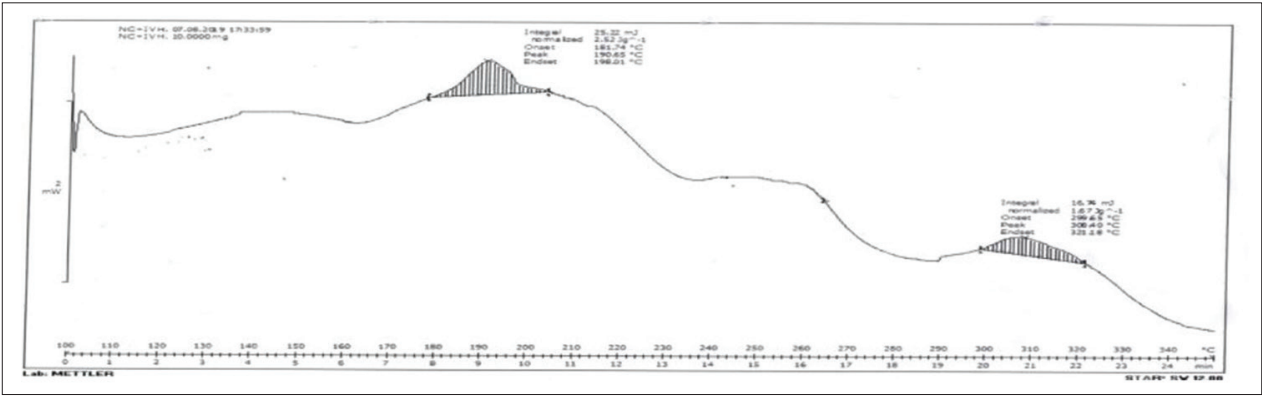

Fig. 9: Differential scanning calorimetry thermogram of ivabradine hydrochloride and nanocellulose

Table 4: Pre-compression characteristics of IVH tablets F1-F8

\begin{tabular}{|c|c|c|c|c|c|}
\hline Formulation code & $\begin{array}{l}\text { Angle of repose } \\
(\theta)\end{array}$ & $\begin{array}{l}\text { Bulk density } \\
\left(\mathrm{g} / \mathrm{cm}^{3}\right)\end{array}$ & $\begin{array}{l}\text { Tapped density } \\
\left(\mathrm{g} / \mathrm{cm}^{3}\right)\end{array}$ & $\begin{array}{l}\text { Compressibility index } \\
\text { (\%) }\end{array}$ & Hausner's ratio \\
\hline F1 & $30.8 \pm 0.2$ & $0.166 \pm 0.001$ & $0.2 \pm 0.008$ & $17 \pm 0.031$ & $1.2 \pm 0.231$ \\
\hline F2 & $30.96 \pm 0.6$ & $0.156 \pm 0.004$ & $0.196 \pm 0.002$ & $20 \pm 0.043$ & $1.25 \pm 0.002$ \\
\hline F3 & $26.56 \pm 0.65$ & $0.163 \pm 0.009$ & $0.192 \pm 0.005$ & $15 \pm 0.058$ & $1.10 \pm 0.315$ \\
\hline $\mathrm{F} 4$ & $27.9 \pm 0.7$ & $0.178 \pm 0.001$ & $0.212 \pm 0.003$ & $16 \pm 0.088$ & $1.19 \pm 0.615$ \\
\hline F5 & $30.11 \pm 0.22$ & $0.166 \pm 0.009$ & $0.20 \pm 0.009$ & $17 \pm 0.174$ & $1.20 \pm 0.012$ \\
\hline F6 & $29.2 \pm 0.77$ & $0.178 \pm 0.003$ & $0.204 \pm 0.004$ & $12 \pm 0.288$ & $1.14 \pm 0.091$ \\
\hline F7 & $21.80 \pm 0.54$ & $0.161 \pm 0.002$ & $0.178 \pm 0.002$ & $9 \pm 0.023$ & $1.10 \pm 0.002$ \\
\hline F8 & $28.36 \pm 0.9$ & $0.192 \pm 0.007$ & $0.212 \pm 0.006$ & $15 \pm 0.068$ & $1.17 \pm 0.415$ \\
\hline
\end{tabular}

Table 5: Results of post-compression characteristics directly compressed tablets of IVH, F1-F8

\begin{tabular}{|c|c|c|c|c|c|c|}
\hline $\begin{array}{l}\text { Formulation } \\
\text { code }\end{array}$ & $\begin{array}{l}\text { Percentage weight } \\
\text { variation }(n=20 \pm S D)\end{array}$ & $\begin{array}{l}\text { Hardness (kg) } \\
(n=3 \pm S D)\end{array}$ & $\begin{array}{l}\text { Percentage drug } \\
\text { content }(n=10 \pm S D)\end{array}$ & $\begin{array}{l}\text { Friability }(\%) \\
(n=10 \pm S D)\end{array}$ & $\begin{array}{l}\text { Disintegration } \\
\text { time }(n=6 \pm S D)\end{array}$ & $\begin{array}{l}\text { Thickness }(\mathrm{mm}) \\
(n=3 \pm S D)\end{array}$ \\
\hline $\mathrm{F} 1$ & $1.76 \pm 0.25$ & $5.2 \pm 0.24$ & $96.59 \pm 0.0016$ & $0.55 \pm 0.0017$ & $6 \mathrm{~min} 30 \mathrm{~s}$ & $3.16 \pm 0.045$ \\
\hline $\mathrm{F} 2$ & $1 \pm 0.05$ & $4.8 \pm 0.16$ & $91.4 \pm 0.0012$ & $0.99 \pm 0.0037$ & $4 \mathrm{~min} 20 \mathrm{~s}$ & $3.29 \pm 0.037$ \\
\hline F3 & $1.83 \pm 1.03$ & $4.2 \pm 0.20$ & $93.75 \pm 0.0016$ & $0.80 \pm 0.0016$ & $7 \mathrm{~min} 5 \mathrm{~s}$ & $3.21 \pm 0.039$ \\
\hline F4 & $3.25 \pm 1.75$ & $5.5 \pm 0.20$ & $95.45 \pm 0.0012$ & $0.66 \pm 0.0024$ & $8 \mathrm{~min} 55 \mathrm{~s}$ & $3.41 \pm 0.027$ \\
\hline F5 & $2.01 \pm 1.09$ & $5.5 \pm 0.12$ & $94.88 \pm 0.0016$ & $0.62 \pm 0.0047$ & $7 \mathrm{~min} 10 \mathrm{~s}$ & $3.26 \pm 0.035$ \\
\hline F6 & $2.5 \pm 0.59$ & $4.8 \pm 0.12$ & $93.18 \pm 0.0037$ & $0.66 \pm 0.0052$ & $6 \min 5 \mathrm{~s}$ & $3.33 \pm 0.046$ \\
\hline F8 & $2.06 \pm 0.99$ & $5.6 \pm 0.21$ & $96.5 \pm 0.0012$ & $0.72 \pm 0.0041$ & $6 \mathrm{~min} 30 \mathrm{~s}$ & $3.28 \pm 0.042$ \\
\hline
\end{tabular}

SD: Standard deviation, IVH: Ivabradine hydrochloride

Table 6: In vitro drug release profile of IVH tablets (F1-F4)

\begin{tabular}{lllll}
\hline \multirow{2}{*}{$\begin{array}{l}\text { Time } \\
\text { (h) }\end{array}$} & \multicolumn{4}{l}{ Cumulative percentage of drug release } \\
\cline { 2 - 5 } & F1 & F2 & F3 & F4 \\
\hline 0 & 0 & 0 & 0 & 0 \\
2 & $1.12 \pm 0.02$ & $4.5 \pm 0.10$ & $33.75 \pm 0.05$ & $21.37 \pm 0.09$ \\
5 & $6.75 \pm 0.10$ & $19.12 \pm 0.09$ & $59.62 \pm 0.06$ & $22.5 \pm 0.03$ \\
8 & $16.87 \pm 0.20$ & $46.12 \pm 0.20$ & $81 \pm 0.09$ & $30.37 \pm 0.02$ \\
10 & $20.25 \pm 0.08$ & $72 \pm 0.05$ & $90 \pm 0.10$ & $50.62 \pm 0.07$ \\
20 & $38.25 \pm 0.06$ & $84.37 \pm 0.07$ & & $60.75 \pm 0.08$ \\
30 & $43.87 \pm 0.05$ & $90 \pm 0.08$ & & $67.5 \pm 0.06$ \\
60 & $48.37 \pm 0.09$ & & & $87.75 \pm 0.05$ \\
90 & $87.75 \pm 0.05$ & & & $91 \pm 0.10$ \\
\hline * $n=3+$ SD. SD: Standard deviation, IVH: Ivabradine hydrochloride
\end{tabular}

Hausner's ratio from 1.2 to 1.25 suggests free-flowing properties of F1F8. Hence, all these formulations are compressed as tablets.

Evaluation studies of directly compressed tablets of IVH

Post-compression characteristics of finished tablets of F1-F8 are given in Table 5. As revealed from the values, the percentage weight variation (1-1.75), hardness (4.1-5.6 kg/cm²), drug content (91.4-98.92), friability (0.55\%-0.99\%), disintegration time (4 min $20 \mathrm{~s}-8 \mathrm{~min} 55 \mathrm{~s}$ ), and thickness (3.12-3.41 $\mathrm{mm}$ ) are in acceptable limits. The percentage drug content values are also satisfactory.

\section{In vitro drug release studies}

The drug release profiles of tablets, F1-F8 and the commercial tablets of IVH are represented in Tables 6 and 7 and in Figs.10 and 11.As 
Table 7: In vitro drug release profile of IVA tablets F5-F8

\begin{tabular}{|c|c|c|c|c|c|}
\hline \multirow[t]{2}{*}{ Time (min) } & \multicolumn{5}{|c|}{ Cumulative percentage of drug release } \\
\hline & F5 & F6 & F7 & F8 & Marketed product \\
\hline 0 & 0 & 0 & 0 & 0 & 0 \\
\hline 2 & $13.5 \pm 0.10$ & $33.75 \pm 0.08$ & $41.62 \pm 0.09$ & $20.25 \pm 0.10$ & 15.55 \\
\hline 5 & $23.62 \pm 0.07$ & $41.62 \pm 0.05$ & $96.37 \pm 0.08$ & $28.12 \pm 0.02$ & 99 \\
\hline 8 & $43.87 \pm 0.08$ & $51.75 \pm 0.02$ & $98.75 \pm 0.05$ & $39.37 \pm 0.07$ & \\
\hline 10 & $50.62 \pm 0.05$ & $67.5 \pm 0.09$ & & $43.87 \pm 0.05$ & \\
\hline 20 & $66.37 \pm 0.07$ & $81 \pm 0.10$ & & $56.25 \pm 0.08$ & \\
\hline 30 & $69.75 \pm 0.03$ & $90 \pm 0.04$ & & $77.62 \pm 0.08$ & \\
\hline 60 & $77.62 \pm 0.06$ & & & $84.37 \pm 0.10$ & \\
\hline 90 & $84.37 \pm 0.07$ & & & $88.87 \pm 0.03$ & \\
\hline
\end{tabular}

Table 8: Kinetics of drug release of formulations F1-F8

\begin{tabular}{|c|c|c|c|c|c|}
\hline \multirow[t]{2}{*}{ Formulation code } & \multicolumn{2}{|c|}{ Regression model drug release kinetics } & \multirow[t]{2}{*}{ Higuchi $\left(R^{2}\right)$} & \multicolumn{2}{|c|}{ Korsmeyer-Peppas } \\
\hline & Zero-order kinetics $\left(R^{2}\right)$ & First-order kinetics $\left(R^{2}\right)$ & & $R^{2}$ & $n$ \\
\hline $\mathrm{F} 1$ & 0.856 & 0.901 & 0.943 & 0.925 & 1.08 \\
\hline F2 & 0.317 & 0.902 & 0.921 & 0.804 & 1.88 \\
\hline F3 & 0.797 & 0.986 & 0.993 & 0.780 & 2.24 \\
\hline $\mathrm{F} 4$ & 0.402 & 0.952 & 0.936 & 0.727 & 1.25 \\
\hline F5 & 0.44 & 0.848 & 0.869 & 0.742 & 1.26 \\
\hline F7 & 0.508 & 0.958 & 0.951 & 0.774 & 2.63 \\
\hline F8 & -0.20 & 0.911 & 0.930 & 0.71 & 1.26 \\
\hline
\end{tabular}

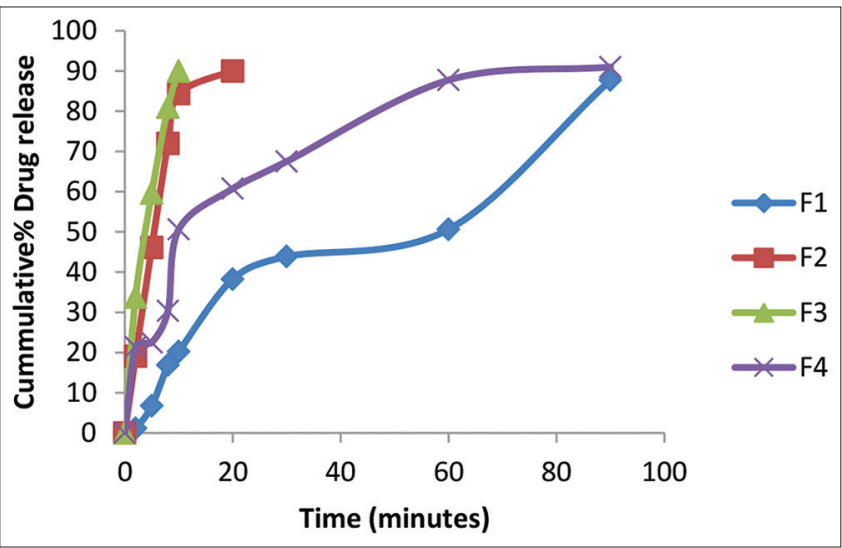

Fig. 10: In vitro drug release profile of different formulations F1-F4

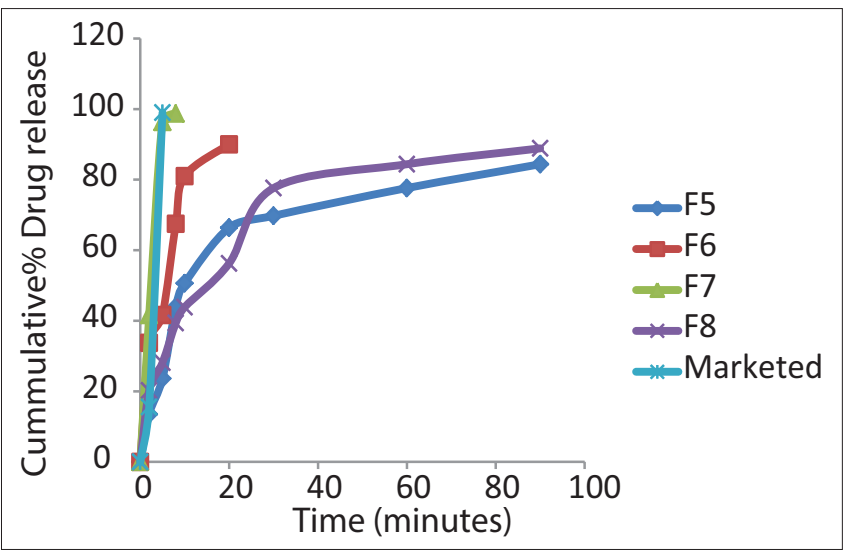

Fig. 11: In vitro drug release profiles ivabradine hydrochloride tablets of formulations F5-F8 and commercial tablet

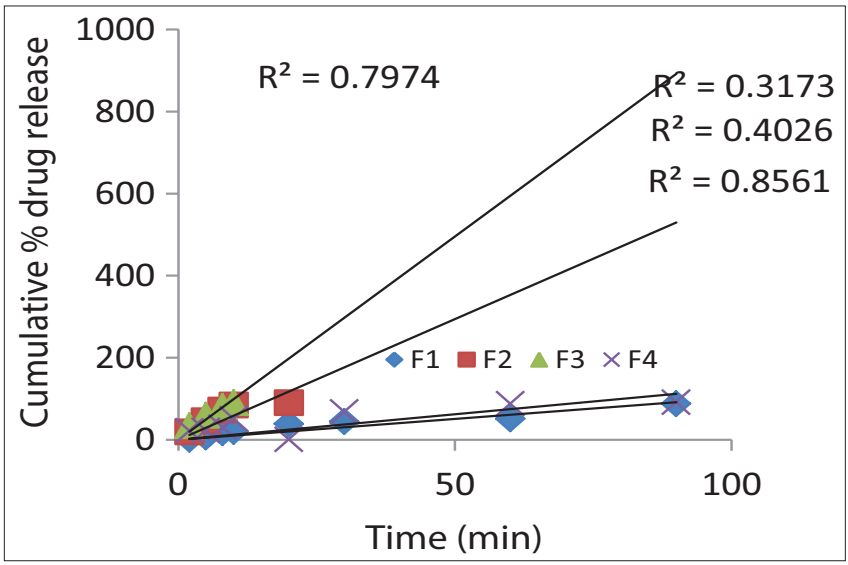

Fig. 12: Zero-order kinetics of formulations F1-F4

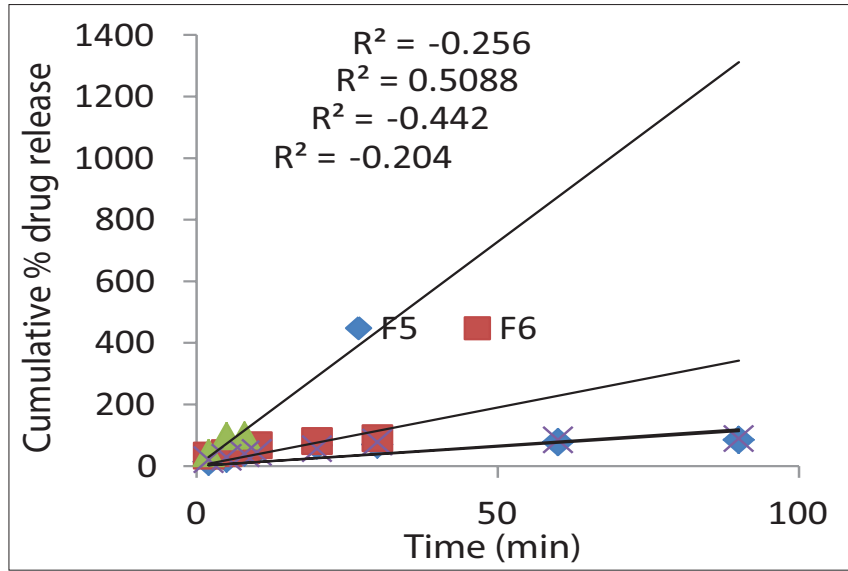

Fig. 13: Zero-order kinetics of formulations F5-F8 


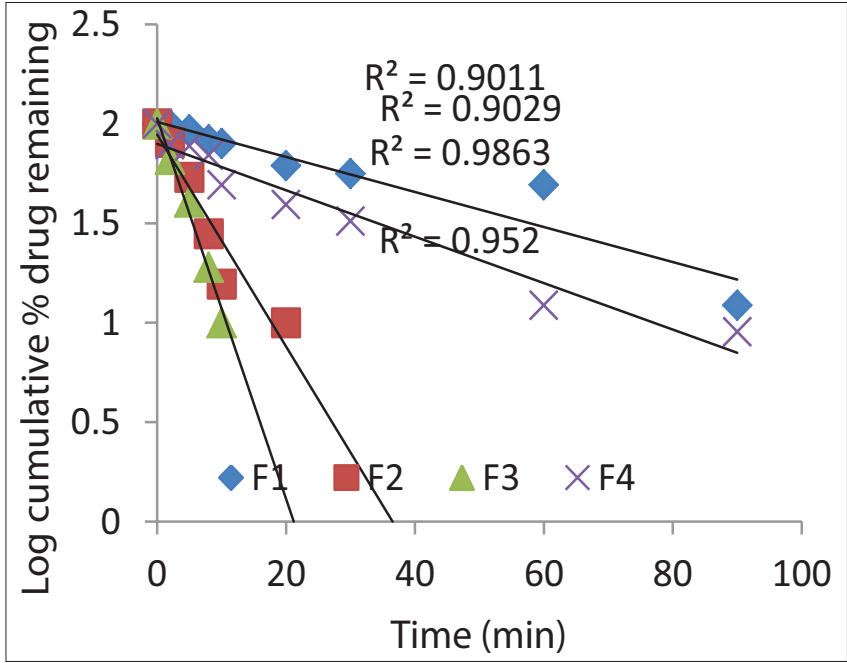

Fig. 14: First-order kinetics of formulations F1-F4

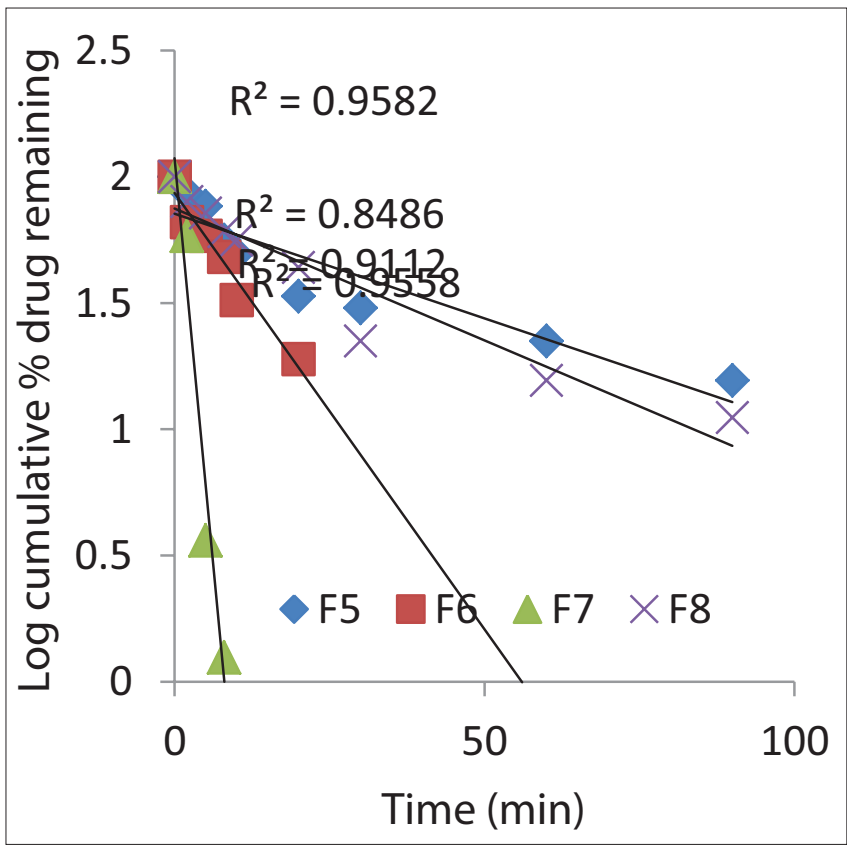

Fig. 15: First-order kinetics of formulations F5-F8

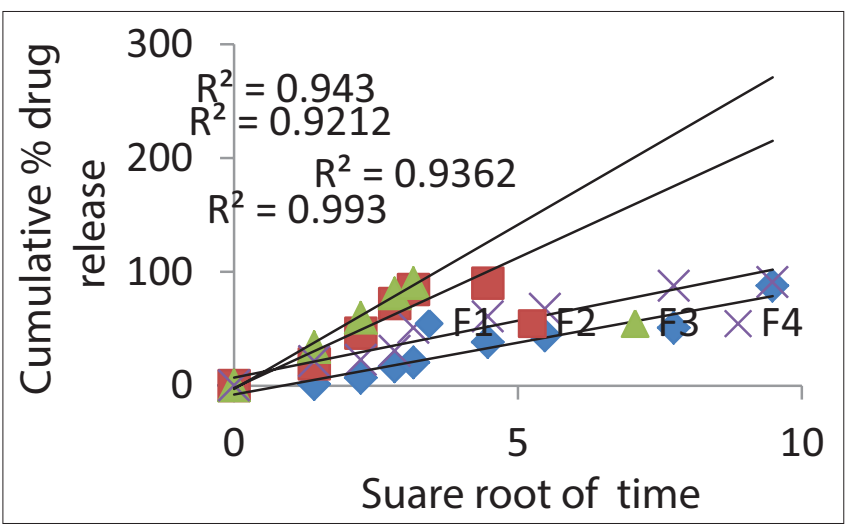

Fig. 16: Higuchi plots of formulations F1-F4

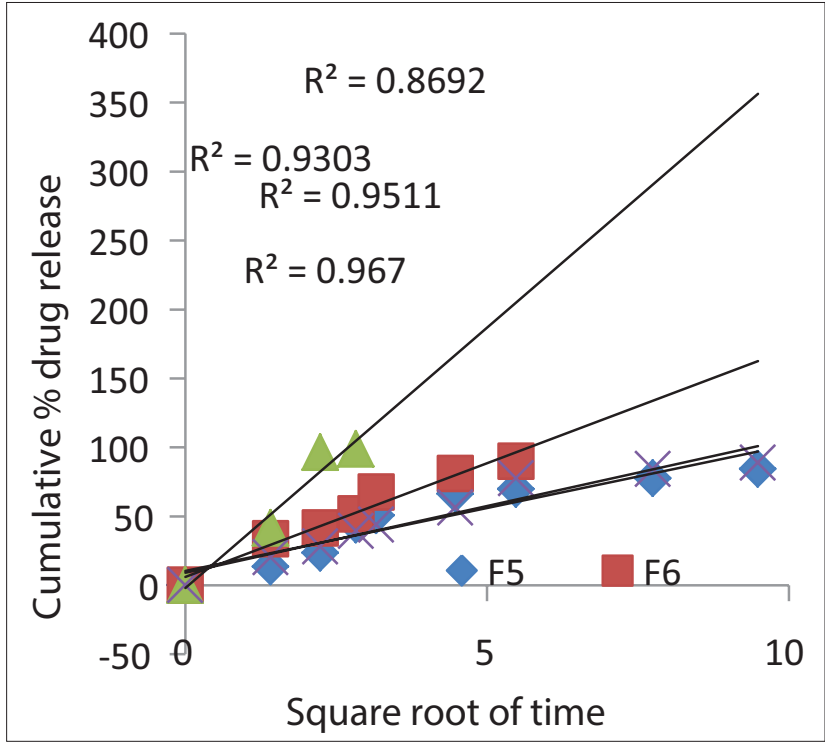

Fig. 17: Higuchi plots of formulations F5-F8

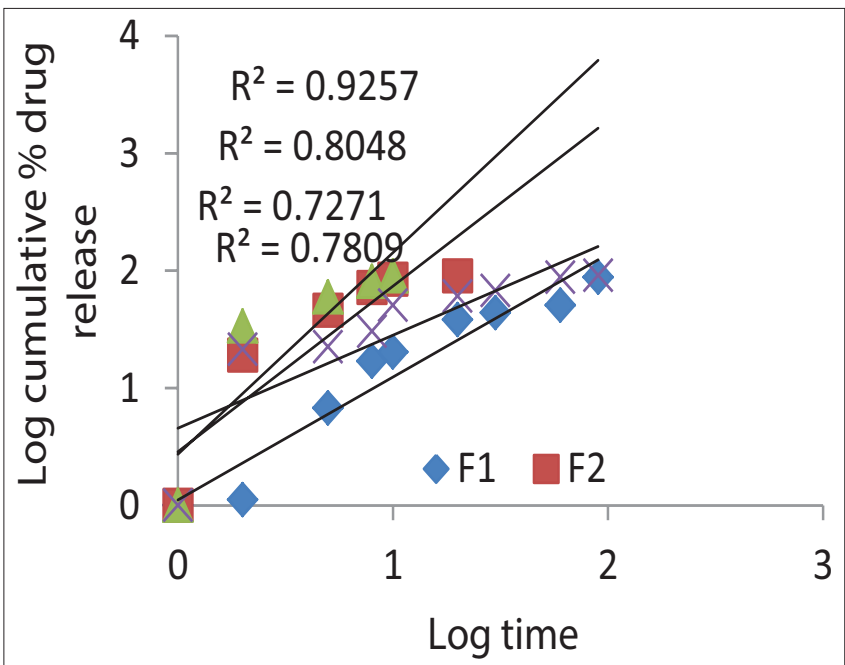

Fig. 18: Korsmeyer-Peppas plots for the formulations F1-F4

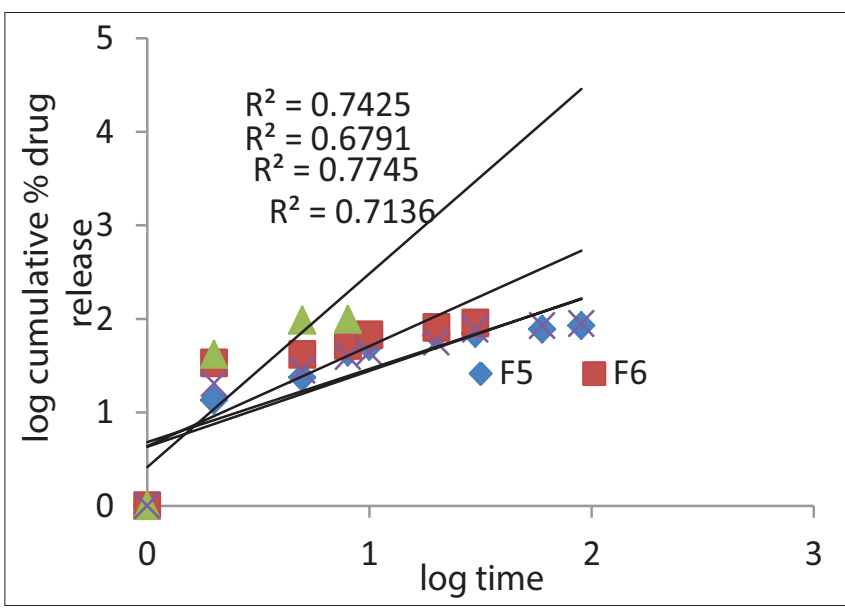

Fig. 19: Korsmeyer-Peppas plots for the formulations F5-F8 
these dissolution profiles show fast release from all the formulations prepared using nanocellulose extracted from

our work. Even though disintegration time and hardness values are high like the values of conventional tablets, the dissolution is fast from all tablets. There is no relationship between dissolution and the values of disintegration time and hardness values. This supports the reports related to independent nature of disintegration time on dissolution as per Q6A of ICH as well as hardness [15]. Here, the commercial tablets of IVH have evidenced it as a fast dissolving tablet with drug $99 \%$ in $5 \mathrm{~min}$. Even in our work, the tablets made using nanocellulose also exhibited fast release and among all the tablet, F7 showed high release of $96.37 \%$ in 5 min and this was considered as a promising formulation.

\section{Kinetics of drug release for all the eight formulations}

Various plots of release kinetics directly compressed tablets of IVH are shown in Figs. 12-19 and respective data of correlation coefficient values are given in Table 8.

As per the results, the regression coefficient values $\left(R^{2}\right)$ of all formulations F1-F8 in case of first-order plots are 0.901, 0.902, 0.986, $0.952,0.955,0.958$, and 0.911 . This indicates the drug release following the first-order kinetics. Similarly, it is evident that the mechanism of drug release is diffusion since the Higuchi plots of F1-F8 are having $R^{2}$ values $0.943,0.921,0.993,0.936,0.869,0.967,0951,0.938$, and 0.917

\section{CONCLUSION}

From all these, it is concluded that nanocellulose can produce successfully by acid and alkali treatment followed by ball milling and lyophilization and can exploit successfully for design of immediate release tablets of IVH.

\section{Scope}

Nanocellulose from plant source will have scope for design of immediate release tablets in case of water-soluble drugs and can have scope for development poorly soluble drugs as conventional release tablet or capsule dosage forms approach for design of fast-release tablets of IVH using nanocellulose similar to the commercially available IVH tablets.

\section{ACKNOWLEDGMENTS}

The authors acknowledge their gratitude to DST-Curie facilities of Sri Padmavati Mahila Visvavidyalayam, Tirupati, for providing FTIR, DSC, and dissolution testing apparatus as and when required for the study.

\section{AUTHORS' CONTRIBUTIONS}

Jeevana Jyothi B has designed the plan of present work and responsible for this novel work and preparation of manuscript. Aparna J has done the experiments involved in the research.

\section{CONFLICTS OF INTEREST}

The authors have declared no conflicts of interest.

\section{REFERENCES}

1. de Oliveira FB, Bras J, Pimenta MT, da Silva Curveloa AA, Belgacemca MN. Production of cellulose nanocrystals from sugarcane bagasse fibers and pith. Ind Crops Prod 2016;93:48-57.

2. Jyothi BJ, Mounika M. Assessment of self-extracted cellulose from Oryza sativa for design of controlled drug delivery system of dalfampridine. Asian J Pharm Clin Res 2019;12:338-45.

3. Mohammed N, Hashim R, Othman S, Asim M. Nanocellulose: Preparation methods and applications. In: Cellulose-reinforced Nanofibre Composites: Production Properties and Application. Amsterdam: Elsevier; 2017. p. 261-76.

4. Punnadiyil RK, Sreejith MP, Purushothaman E. Isolation of microcrystalline and nano cellulose from peanut shells. J Chem Pharm Sci 2016;1:12-6.

5. Zango ZU, Imam SS. Evaluation of microcrystalline cellulos from groundnut shell for the removal of crystal violet and methylene blue. Nanosci Nanotechnol 2018;8:1-6.

6. Azubuike CP, Odulaja JO, Okhamafe AO. Physicotechnical, spectroscopic and thermogravimetric properties of powdered cellulose and microcrystalline cellulose derived from groundnut shells. J Excip Food Chem 2012;3:106-12.

7. Vora R, Shah Y. Extraction, characterization of micro crystalline cellulose obtained from cornhusk using different acid alkali treatment method. Indo Am J Pharm Sci 2017;4:2349-99.

8. Bano S, Negi YS. Studies on cellulose nano-crystal isolated from groundnut shells. Carbohydr Polym 2017;157:1041-9.

9. Albrecht S. The pathophysiology and treatment of stable angina pectoris. US Pharm 2013;38:43-60.

10. Anand Raj LF, Shanmugapriya R, Jeslin J. Biosynthesis of cellulose microfiber from peanut shell for the preparation of bio-nanocomposite films for food-packaging application. Bull Mater Sci 2019;42:63.

11. Suryawanshi T, Nair V, Patel P, Gupta AD. Extraction of cellulose and bio-fuel production from groundnut shells and its application to increase crop yield. World J Pharm Pharm Sci 2017;6:1820-31.

12. Kharismi RA, Sutriyo S, Suryadi H. Preparation and characterization of microcrystalline cellulose produced from betung bamboo (Dendrocalamus asper) through acid hydrolysis. J Young Pharm 2018;10:79-83.

13. Moran JI, Alvarez VA, Cyras VP, Analia V. Exraction of cellulose and preparation of nanocellulose from sisal fibers. Cellulose 2008; $15: 149-59$

14. Indian Pharmacopoeia. The Indian Pharmacopoeia Commission, Ghaziabad. Vol. 1. India: Government of India, Ministry of Health and Family Welfare; 2007. p. 183.

15. Gupta A, Hunt RL, Shah RB, Sayeed VA, Khan MA. Disintegration of highly soluble immediate release tablets: A surrogate for dissolution. AAPS Pharm Sci Tech 2009;10:495-9 